\title{
Validation of the multidimensional sense of humor scale in people with chronic kidney disease
}

\author{
Luis M.M. Sousa ${ }^{1,2}$, Cristina M.A. Marques-Vieira ${ }^{3}$, Sandy S.P. Severino ${ }^{* 1,2}$, Juan L. Pozo-Rosado ${ }^{4}$, Ana Vanessa \\ Antunes ${ }^{1}$, Helena M.G. José 5 \\ ${ }^{1}$ Atlântica School of Health Sciences, Atlântica University, Oeiras, Portugal \\ ${ }^{2}$ Curry Cabral Hospital, Central Lisbon Hospital Center, Lisbon, Portugal \\ ${ }^{3}$ School of Nursing of the Institute of Health Sciences, Catholic University of Portugal, Lisbon, Portugal \\ ${ }^{4}$ Fernando da Fonseca Hospital, Lisbon, Portugal \\ ${ }^{5}$ Polytechnic Health Institute of Multiperfil, Luanda, Angola
}

Received: September 2, 2017

DOI: $10.5430 /$ jnep.v8n3p72
Accepted: November 9, $2017 \quad$ Online Published: November 14, 2017

URL: https://doi.org/10.5430/jnep.v8n3p72

\begin{abstract}
Multidimensional Sense of Humor Scale (MSHS) was developed by Thorson and Powell and it was validated in Portuguese, but not in people with chronic kidney disease (CKD). This study examined the psychometrics of the MSHS in people with CKD on hemodialysis. A random sample of 171 people with CKD undergoing hemodialysis was selected. Exploratory Factor Analysis revealed a structure with three factors, "Humor Production and Social Use of Humor", "Adaptive Humor and Appreciation Humor" and "Attitude Towards Humor", with Alpha Cronbach values of 0.93, 0.90 and 0.83 respectively. It revealed stability in both interview and questionnaire methods. It showed moderate positive correlations with Positive Affect, Subjective Happiness and Wellbeing Personal Index, and moderate negative correlation with Negative Affect. Therefore, MSHS shows evidence of being a valid, reliable and reproducible scale either by questionnaire or interview.
\end{abstract}

Key Words: Chronic renal insufficiency, Validation studies, Psychometrics, Wit and humor as topic, Nursing

\section{INTRODUCTION}

Chronic kidney disease (CKD) is a general term for heterogeneous disorders disturbing kidney structure and function. Disease and management are classified according to stages of disease severity, which are assessed from glomerular filtration rate and albuminuria, and clinical diagnosis (cause and pathology). ${ }^{[1]}$ Hemodialysis (HD) is the therapy most often used in terminal stage CKD, which involves the removal of nitrogenized toxic substances from the blood and liquid excesses retained in the tissues of the body. ${ }^{[2]}$ Patients on hemodialysis (HD) are thought to be highly susceptible to emotional problems because of the chronic stress related to disease burden, dietary restrictions, functional limitations, associated chronic illnesses, adverse effects of medications, changes in self-perception and fear of death. ${ }^{[3]}$ In this sense, hemodialysis influences psychological, physical and social aspects of life. ${ }^{[4]}$

Taking into account the high levels of depression, disability and impaired immunity in people with chronic kidney disease, ${ }^{[3,5]}$ the humor helps a person cope with kidney disease and can be a key component in the quality of life of people on hemodialysis. In a study conducted in Norway, with 52

\footnotetext{
* Correspondence: Sandy S.P. Severino; Email: sandyseverino@gmail.com; Address: Atlântica School of Health Sciences, Atlântica University, Oeiras, Portugal.
} 
persons undergoing hemodialysis followed for two years, it was found that higher levels of sense of humor had a negative association with stressors and mortality related to the disease. ${ }^{[5]}$

Humor is a construct that is closely related to well-being and is considered a complex phenomenon, clearly personal in nature. The standard sense of humor varies from person to person and changes according to the humor, the personality, the situation, the level of attention, the importance given to the situation, among other things. ${ }^{[6]}$ The main benefits of humor in people's health are to promote physical and psychological well-being and improve of the perceived health, it helps address chronic disease, reducing pain, stress, anxiety, stress relief and strengthens immune system. ${ }^{[7]}$

Within the context of CKD nurses have a fundamental role by working collaboratively with other health professionals to achieve the competent and consistent care required by the complexity of treatment. The Nursing Intervention Classification (NIC) describes humor has a nursing intervention that allows the professional to help patients to understand, appreciate and express funny, entertaining or humorous situations, in order to release anger and tension, facilitate learning, contributing for health promotion and maintenance, therefore, helping patient dealing with feelings related to treatment. ${ }^{[7,8]}$ Other authors state that humor develops communication and the relationship between the nurse and the patient, it helps manage emotions, decreases tension and improves the experience in the caregiving setting. ${ }^{[9,10]}$

The use of humor as a planned and intentional nursing intervention must take into account a set of considerations related to the nature of the humor, namely its individual, personal and paradoxal character and its properties. ${ }^{[7]}$

Within the framework of humor, the nurse must take into consideration the type of resources that the person has, especially if they like to play, to laugh, to have someone make them laugh, be with people with a sense of humor, to listen to anecdotes and funny stories, as well as, to read comic books since these resource influence humor assessment. ${ }^{[11]}$

The Multidimensional Sense of Humor Scale (MSHS) was developed by Thorson and Powell. ${ }^{[12]}$ In this study the sense of humor was presented as a multidimensional construct. The 24-item scale showed a Cronbach's $\alpha$ of 0.92, comprising the dimensions "Social production and use of humor", "Adaptive humor", "Appreciation of the humor" and "Attitude toward humor". [12] This scale has been validated in several languages and cultures, particularly in the fol- lowing countries: United States of America (USA), ${ }^{[12-14]}$ Croatia, ${ }^{[15]}$ Australia, ${ }^{[16]}$ Spain, ${ }^{[17]}$ Portugal, ${ }^{[6,18]}$ China $^{[19]}$ and Mexico. ${ }^{[20]}$ Factor analysis has showed some differences in the first study; ${ }^{[12]}$ in a sample of elderly from the USA six factors emerged, that were not present in young people (four factors) ${ }^{[14]}$ in Croatia ${ }^{[15]}$ the validation study resulted in a scale with five factors identical to the Portuguese version. ${ }^{[6]}$ Concerning construct validity, some studies conducted Exploratory Factorial Analysis (AFE) with principal components analysis and Varimax Rotation; ${ }^{[6,12-15,18,19]}$ or maximum likelihood method with Oblique Rotation ${ }^{[16]}$ and Confirmatory Factorial Analysis (AFC). ${ }^{[20]}$

In all cultures the reliability assessed by Cronbach's $\alpha$ showed values above 0.70 , except for the Mexican version, in which two dimensions, "adaptive humor/coping" and "enjoy life" presented a 0.53 and 0.56 result, respectively. The stability and reproducibility was studied only in the sample from Australia, ${ }^{[16]}$ through test-retest. In the study of discriminant validity, MSHS was able to discriminate by gender ${ }^{[14]}$ and age. ${ }^{[6,14,17,18]}$

Hereupon, the aim of this study is to verify that MHSH keeps the psychometric properties of validity and reproducibility in people with CKD under hemodialysis program. We also intend to verify the association between sense of humor and well-being. ${ }^{[19]}$ Thus the concurrent validity study aims to find out if MSHS is correlated with psychological well-being measures: Positive Affection and Negative Affection; ${ }^{[21]}$ Subjective Happiness; ${ }^{[22]}$ and Satisfaction with Life in General. $^{[23]}$

\section{METHOD}

\subsection{Study design and setting}

An exploratory and cross sectional study on the psychometric properties $^{[24]}$ of the MHSH was carried out in two Diaverum Clinics located in Lisbon, Portugal between May and June 2015. The study of reliability was performed with two separate evaluations, with the last evaluation (Test Retest) being performed 48 to 96 hours after the first.

\subsection{Subjects}

The population consisted of people with CKD undergoing hemodialysis program. We established the following inclusion criteria: people diagnosed with CKD, undergoing hemodialysis for at least six months, and above 18 years of age. Exclusion criteria were the following: people with cognitive impairment and active psychiatric disease because of the difficulty in answering the questionnaire, with some patients refusing and demonstrating aggressive behavior. This information was retrieved from patient's medical records. 
The initial sample consisted of 248 patients that met the inclusion criteria (139 in Clinic 1 and 114 in Clinic 2). A randomized probability technique was used for sampling (random without replacement). The sample calculation with a Confidence Interval of $95 \%$ and sample error of 5\% indicated a necessary sample of 192 patients (103 in Clinic 1 and 89 in Clinic 2). Afterwards, a random selection without replacement was made. Regarding Clinic 1, six patients refused to participate, two were hospitalized and two dropped out. In Clinic 2, five patients refused to participate, two were hospitalized and five dropped out. After this process a total of 171 patients were included in the study: 93 from Clinic 1 (89\%) and $78(88 \%)$ Clinic 2.

\subsection{Data collection}

Data were collected through self-administered questionnaires, and interviews were conducted face to face by five trained researchers. The researchers were chosen and were submitted to specific training. This training consisted of the explanation of the objectives of the study and the various criteria; also, a guide regarding the correct filling of the questionnaire was given to each of the researchers. Both were performed during the haemodialysis session.

For data collection the following instruments were used: Portuguese version of the Multidimensional Sense of Humor Scale (MSHS), ${ }^{[6]}$ Positive Affect and Negative Affect measured by the Portuguese version of the Positive and Negative Affect Schedule (PANAS), ${ }^{[21]}$ Subjective Happiness by Portuguese version of the Subjective Happiness Scale (SHS), ${ }^{[22]}$ Satisfaction With Life in General (SWLG), obtained by the Wellbeing Personal Index (WPI) ${ }^{[23]}$ and a tool to identify the sample demographic and clinical characteristics (age, gender, nationality, educational level, occupation, marital status, duration of dialysis, presence of hypertension and diabetes). The MSHS is an instrument consisting of 24 items that assess the multidimensional aspects of sense of humor, considering four dimensions (humor production; coping or adaptive humor; appreciation of humor and attitudes towards humor and humorous people). ${ }^{[12]}$ It is presented in the form of a 5-points Likert scale, ranging from 1 (strongly agree) to 5 (strongly disagree). The MSHS presented an interpretable factor structure globally consistent with studies conducted in other samples, with satisfactory internal consistency values and can be considered a valid instrument to characterize individuals with regard to their "humorous state" and can describe the sense of humor in its different dimensions. ${ }^{[6]}$ The internal reliability assessed by Cronbach's $\alpha$ in factor I "Production and Social Use of Humor" is 0.93 , in the II factor "Adaptive Humor" is 0.84 , the factor III "Negation to Use Humor" is 0.63 , in the fourth factor "Attitude toward
Humor" is 0.74 and the factor V "Appreciation of Humor" is $0.71{ }^{[6,18]}$

The PANAS consists of two subscales: Positive Affect and Negative Affect, each with 10 items, wherein the constructs are evaluated on a 5-points Likert Scale. Both Positive and Negative Affect dimensions can get a maximum score of 50 points. In the Portuguese version, the psychometric properties of PANAS in people with CKD, (similarly to the original scale) reveals the existence of two factors, internal consistency with Cronbach's $\alpha$ of 0.86 (in the original, $\alpha=0.88$ ) for the scale of Positive Affect and 0.88 (in the original, $\alpha$ $=0.87$ ) for the scale of Negative Affect. ${ }^{[21]}$ The SHS is composed of four items: within two items (two and three) respondents are asked to characterize and compare themselves with others, both in absolute and relative terms; the two other items correspond to descriptions of happiness and unhappiness. On this scale, respondents are asked to indicate to which extent the statements characterize them, and the answer is given on a visual analogue scale with seven points, founded on two opposing statements that express the level of happiness or lack of it. The Portuguese version in people with CKD presents a single factor with internal reliability with Cronbach's $\alpha$ of $0.90 .{ }^{[22]}$ The SWLG/WPI consists of seven items/subjects (satisfaction with standard of living, health, personal development, personal relationships, sense of security, connection to the community, and security for the future) that intend to assess the "satisfaction with life in general". For each item, it is asked for participants to classify their satisfaction with each item on a scale that ranges from " 0 " (extremely dissatisfied) to "10" (extremely satisfied), where " 5 " means neutral. The WPI is calculated on a score of 0-100 (maximum range percentage). The exploratory factor analysis of the Portuguese version in people with CKD shows the existence of a single factor, with an internal reliability with Cronbach's $\alpha$ of $0.82 .{ }^{[23]}$

\subsection{Ethical approval}

This study was approved by the Diaverum Ethics Committee (approval No 1/2015). All participants were fully informed and freely signed a consent form to ensure the confidentiality of their data and the right of withdrawal, without repercussions to themselves.

\subsection{Data analysis}

Statistical analysis was performed using the Statistical Package for Social Sciences (SPSS) version 20.0. In the evaluation of the psychometric properties, the study of reliability was made through the Cronbach $\alpha$. To evaluate the stability we used the intraclass correlation coefficient (ICC) and coefficient of Spearman-Brown correlation ${ }^{[25]}$ in Test Retest 
(after 48 to 96 hours for 40 randomly selected people, 26 by questionnaire and 14 by interview). A minimum value of 0.70 was adopted as a satisfactory internal consistency. ${ }^{[25]}$ On what concerns the validity study, Exploratory Factor Analysis (EFA) was performed through maximum likelihood method, with Variamax Rotation. Adequacy was assessed by Kaiser-Meyer-Olkin (KMO) and Bartlett's test of sphericity.

Convergent validity was assessed by a Pearson correlation between MSHS, PANAS, SHS and WPI. Sense of humor is encompassed in wellbeing. It is comprised by a range of phenomena which include emotional responses, satisfaction and global satisfaction with life. The components of SWB are pleasant affect (i.e. joy, contentment, pride, affection and happiness); unpleasant affect (i.e. guilt and shame, anxiety, worry, anger, stress and depression); life satisfaction (i.e. desire to change, satisfaction with life - current, past and future); and satisfaction (i.e. work, family, leisure, health, finances and self). ${ }^{[26]}$ To verify the predictive validity of the MHSH dimensions a hierarchical multiple regression analysis was made with the scores of 3 dimensions (Humor Production and Social Use of Humor; Adaptive Humor and Humor Appreciation and Attitude Towards Humor) as dependent variables. The independent variables of age and gender were inserted into the equation in step 1. Scores of PANAS, SHS and WPI were later introduced in the regression equation (step 2). Categorical variables were expressed as percentages or absolute values; continuous variables as means \pm standard deviation. The significance level was set at $p<.05$.

A request for the use of the Portuguese versions of PANAS, SHS and WPI was send to the author, and permission was therefore granted.

\section{RESUlTS}

\subsection{Reproducibility}

The sample consists of 171 patients diagnosed with CKD, with data being collected from 88 interviews (51.5\%) and 83 questionnaires (48.5\%), with an average age of 60.20 $( \pm 14.34)$ years, mostly men $(61 \%)$. The nationality of the patients is distributed in the following way: most patients are Portuguese $(80.1 \%)$, followed by Cape Verde $(14 \%)$, Sao Tome (3.5\%), Angola (1.8\%) and Guinea (0.6\%). As for education, $3.6 \%$ are illiterate, $42.9 \%$ have the 4 th grade, $18.5 \%$ the 6 th grade, $14.9 \%$ the 9 th grade, $11.3 \%$ the 12 th grade and $8.9 \%$ university education. In this sample $25.9 \%$ of the patients are single, $56.5 \%$ married, $11.8 \%$ widowed and $5.9 \%$ divorced. Concerning occupation, $76.7 \%$ are re- tired and $23.3 \%$ have a regular job. Regarding health data, patients undergo hemodialysis for 72.17 ( \pm 54.2) months, $62.1 \%$ have high blood pressure and $27.1 \%$ Diabetes.

The analysis of the psychometric properties presented the following results: for the reproducibility of MSHS, (verified by Cronbach $\alpha$ coefficient) the dimension "Humor Production and social use of humor" ranged from 0.92 to 0.94 , the dimension "Adaptive Humor and appreciation of humor" ranged from 0.87 to 0.90 and dimension "Attitude Towards Humor" ranged from 0.80 and 0.82 , after the exclusion of each item; for the stability study (Test Retest), data obtained by questionnaire $(n=26)$ showed a global Cronbach's $\alpha$ in the first evaluation of 0.89 and second evaluation of 0.90 . The Spearman-Brown correlation coefficient was 0.90 and the ICC was 0.94 [ICC 95\%; 0.90 to $0.97 ; p<.0001$ ]. Per interview $(\mathrm{n}=14)$ overall Cronbach's $\alpha$ in the first evaluation was 0.89 and the second evaluation was 0.87 . The Spearman-Brown correlation coefficient was 0.74 and the ICC was 0.92 [95\% ICC; 0.84 to $0.97 ; p<.0001$ ], showing good consistency and stability between evaluations, both through self-applied questionnaire and interview.

\subsection{Validity}

The exploratory factorial analysis $(\mathrm{KMO}=0.92$; Bartlett sphericity test $\chi^{2}$ [276] 2753.047, $p<.001$ ) showed a threedimensional factor solution, which accounted for $63.0 \%$ of the explained variance of the construct. All items were loaded into factors with appropriate factor loadings (ie > 0.5 , see Table 1 ). The commonalities (h2) ranged between 0.28 and 0.80 . The Cronbach $\alpha$ coefficient of the overall scale was 0.93 .

In the study of convergent validity, Humor Production and Social Use of Humor has a strong positive correlation with Adaptive Humor and Humor Appreciation and moderate positive with Attitude Towards Humor, Positive Affect, Subjective Happiness and Satisfaction with Life in General. Adaptive Humor and Humor Appreciation presents moderate positive correlations with Attitude Towards Humor, Positive Affect, Subjective Happiness and Satisfaction with Life in General; and moderate negative with Negative Affect. The Attitude Towards Humor presents moderate positive correlations with Positive Affect, Subjective Happiness and Satisfaction with Life in General and moderate negative with Negative Affect (see Table 2).

Table 3 shows the results regarding the predictive validity, in order to identify whether the PA, NA, SH and GSWL predicts MSHS dimensions, using gender and age as variables. 
Table 1. Exploratory factorial analysis of the MSHS in patients diagnosed with CKD undergoing hemodialysis, Lisbon, Portugal, 2015

\begin{tabular}{|c|c|c|c|c|}
\hline & \multirow{3}{*}{ Items of the MSHS scale } & \multirow{3}{*}{$\begin{array}{l}\text { Factor } \\
1 \\
\text { HPSUH* }\end{array}$} & \multirow{2}{*}{$\begin{array}{l}\text { Factor } \\
2\end{array}$} & \multirow{2}{*}{$\begin{array}{l}\text { Factor } \\
3\end{array}$} \\
\hline & & & & \\
\hline & & & AHHA $\dagger$ & ATH $\ddagger$ \\
\hline 1. & I'm regarded as something of a wit by my friends & 0.60 & & \\
\hline 2. & I can say things in such a way as to make people laugh & 0.63 & 0.41 & \\
\hline 3. & My clever sayings amuse others & 0.75 & & \\
\hline 4. & People look to me to say amusing things & 0.78 & & \\
\hline 5. & I use humor to entertain my friends & 0.78 & & \\
\hline 6. & I'm confident that I can make other people laugh & 0.53 & & \\
\hline 7. & Other people tell me that I say funny things & 0.78 & & \\
\hline 8. & Sometimes I think up jokes or funny stories & 0.63 & 0.42 & \\
\hline 9. & I can often crack people up with the things I say & 0.85 & & \\
\hline 10. & I can ease a tense situation by saying something funny & 0.70 & 0.42 & \\
\hline 11. & I can have some control over a group of people by my uses of humor & 0.68 & 0.36 & \\
\hline 12. & Humor helps me cope & 0.52 & 0.66 & \\
\hline 13. & Uses of wit/humor help me master difficult situations & 0.53 & 0.63 & \\
\hline 14. & Coping by using humor is an elegant way of adapting & 0.31 & 0.68 & \\
\hline 15. & Trying to master situations through uses of humor is really dumb & & & 0.64 \\
\hline 16. & Humor is a lousy coping mechanism & & & 0.63 \\
\hline 17. & Uses of humor help to put me at ease & 0.43 & 0.62 & \\
\hline 18. & I can use wit to help adapt to many situations & 0.48 & 0.65 & \\
\hline 19. & I appreciate those who generate humor & & 0.65 & \\
\hline 20. & I like a good joke & & 0.62 & \\
\hline 21. & Calling somebody a "comedian" is a real insult & & & 0.59 \\
\hline 22. & I dislike comics & & & 0.65 \\
\hline 23. & People who tell jokes are a pain in the neck & & & 0.74 \\
\hline \multirow[t]{4}{*}{24.} & I'm uncomfortable when everyone is cracking jokes & & & 0.76 \\
\hline & Proper numbers (Eigenvalue) & 10.38 & 3.109 & 1.640 \\
\hline & Explained variance & $43.3 \%$ & $12.9 \%$ & $6.8 \%$ \\
\hline & Alpha coefficient & 0.93 & 0.90 & 0.83 \\
\hline
\end{tabular}

*HPSUH $=$ Humor Production and Social Use of Humor. †AHHA = Adaptive Humor and Humor Appreciation. $\neq$ ATH = Attitude towards Humor.

Table 2. Association between well-being variable and multidimensional sense of humor, and reliability of measurements. Lisbon, Portugal, 2015

\begin{tabular}{|c|c|c|c|c|}
\hline & HPSUH* & $\overline{\mathrm{AHHA}} \dagger$ & ATH & Cronbach $\alpha$ \\
\hline HPSUH* & & & & 0.93 \\
\hline AHHA $†$ & $0.73 \S$ & & & 0.90 \\
\hline ATH $\ddagger$ & $0.23 \|$ & $0.30 \S$ & & 0.83 \\
\hline PAף & $0.42 \S$ & $0.35 \S$ & $0.20 * *$ & 0.86 \\
\hline $\mathrm{NA \dagger \dagger}$ & -0.12 & $-0.26 \|$ & $-0.21 \|$ & 0.88 \\
\hline SH 杆 & $0.45 \S$ & $0.35 \S$ & $0.32 \S$ & 0.90 \\
\hline SWLG/WPI§§ & $0.32 \S$ & $0.22 \|$ & $0.19^{* *}$ & 0.85 \\
\hline
\end{tabular}

*HPSUH $=$ Humor Production and Social Use of Humor. $\uparrow$ AHHA = Adaptive Humor and Humor Appreciation. $\ddagger$ ATH $=$ Attitude Towards Humor, $\S p<.001 . \| p<.01 . q$ PA $=$ Positive Affect. ${ }^{* *} p<.05 . \dagger+\mathrm{NA}=$ Negative affect. $\$$ \$SH = Subjective Happiness. $\S \S S W L G / W P I=$ Satisfaction with Life in General $/$ Wellbeing Personal Index. 
According to the results, production of humor and social use of humor have as predictive variables positive affect and subjective happiness. Adaptive Humor and Humor Appreciation has as predictive variables gender, positive and negative affect and subjective happiness. Adaptive Humor and Humor Appreciation are positively influenced by positive affect and subjective happiness and negatively influenced by negative affect. Attitude Towards Humor has as predictive variables negative affect and subjective happiness. The Attitude Towards Humor is negatively influenced by negative affect and positively influenced by the subjective happiness. Age and Satisfaction with Life in General do not influence the sense of humor in patient diagnosed with CKD.

Table 3. Multiple linear regression adjusted for variables associated with the sense of humor. Lisbon, Portugal, 2015

\begin{tabular}{|c|c|c|c|c|c|c|}
\hline \multirow{2}{*}{ Predictors } & \multicolumn{2}{|l|}{ HPSUH* } & \multicolumn{2}{|l|}{ AHHA $\dagger$} & \multicolumn{2}{|l|}{ ATH: } \\
\hline & B Step 1 & B Step 2 & B Step 1 & B Step 2 & B Step 1 & B Step 2 \\
\hline Age & 0.014 & 0.098 & 0.024 & 0.074 & -0.016 & 0.039 \\
\hline Gender & -0.131 & -0.101 & $-0.188 \S$ & $-0.172 \S$ & -0.117 & -0.106 \\
\hline $\mathrm{PA} \|$ & & 0.2879 & & 0.2929 & & 0.116 \\
\hline $\mathrm{NA}^{* *}$ & & -0.091 & & -0.2839 & & $-0.210 \dagger \dagger$ \\
\hline SH (SHS) 杮 & & 0.3319 & & $0.219 \S$ & & $0.308 \dagger \dagger$ \\
\hline GSWL/WPI§§ & & 0.037 & & -0.041 & & -0.090 \\
\hline $\mathrm{F}$ & 1.393 & $16.942 \pi$ & 2.909 & 13.3689 & 1.160 & 7.2479 \\
\hline Adj. R-Sq & 0.005 & 0.288 & 0.023 & 0.255 & 0.002 & 0.014 \\
\hline R-Sq Change & 0.017 & 0.298 व & 0.035 & 0.2479 & 0.137 & 0.154 ף \\
\hline
\end{tabular}

\section{Discussion}

\subsection{Reproducibility}

This scale shows evidence of being reliable and reproducible in the studied population. The reliability values were similar to the original version $(\alpha=0.92),{ }^{[12]}$ US samples $(\alpha=0.91),{ }^{[13,14]}$ Croatia $(\alpha=0.88),{ }^{[14]}$ Australia $(\alpha=$ 0.92), ${ }^{[16]}$ Spain $(\alpha=0.89),{ }^{[17]}$ Portugal $(\alpha$ ranged from 0.63 to 0.93$),{ }^{[6,18]}$ China $(\alpha=0.88)^{[19]}$ and Mexico $(\alpha=0.91){ }^{[20]}$ The $\alpha$ values obtained in this study are considered good. ${ }^{[25]}$ With respect to stability, this range is reproducible in both data collection methods (questionnaire and interview). In the study conducted in Australia the Test-Retest was $0.83 .{ }^{[15]} \mathrm{In}$ this study, the test-retest values are greater than 0.7 which indicates a good stability of measurements. ${ }^{[25]}$

\subsection{Validity}

All items were loaded on three factors, with factor loadings above 0.53 . The results differ from the original version that had four factors, ${ }^{[12]}$ as well as, versions in US samples, ${ }^{[13]}$ China $^{[19]}$ and Mexico. ${ }^{[20]}$ Nevertheless, in a US ${ }^{[14]}$ study performed on young and old people, six factors were found concerning the elderly sample. On the other hand in two studies undertaken in Croatia ${ }^{[25]}$ and Portugal ${ }^{[6,18]}$ five factors were found, which shows the multifaceted character of humor. Usually elderly people are not exposed to a comedy panoply provided through digital tools. The humor may have had less emphasis on their life experience and therefore has less importance. This may explain both the differences in the production of humor, as well as the appreciation of humor and humorous people. ${ }^{[14]}$ Such differences may indicate that sense of humor varies between cultures. ${ }^{[19]}$ However, we found a common aspect in all versions: the main factor combines humor production/creativity and social use of humor. The explained variance of the three factors has a value greater than $50 \%$ and a KMO greater than 0.70 which shows adjusted measures to the data set. ${ }^{[25]}$ The explained variance is similar to the obtained in the US $(61.5 \%)^{[12]}$ and Portuguese version $(65.22 \%)^{[6,18]}$ and is superior to that found in studies from Croatia (55.9\%), ${ }^{[15]}$ Australia (47.75\%) ${ }^{[16]}$ and China $(53.67 \%) .{ }^{[19]}$ In convergent validity, such as sense of humor, it is associated with the general well-being. This association is also discussed by the authors of the Chinese ${ }^{[19]}$ version of MSHS: "Humor Production and Social Use of Humor" is associated positively to Positive Affect, Subjective Happiness and Satisfaction with Life in General; "Adaptive Humor and Humor Appreciation" and "Attitude Towards Humor" are positively associated with Positive Affect, Subjective Happiness and Satisfaction with Life in General and negatively to Negative Affect. Regarding predictive validity, "Adaptive Humor and Humor Appreciation" gets higher values in women. In a previous study ${ }^{[14]}$ differences were also found between men and women, as men had higher values on some 
items of Production and Social Use of Humor. Age was not predictive of sense of humor. It showed clear differences in a US sample. ${ }^{[14]}$ The "Humor Production and Social Use of Humor" presents higher values in people with CKD who had higher scores on the Subjective Happiness and Positive Affect. The "Adaptive Humor and Humor Appreciation" is positively influenced by the Positive Affect and Subjective Happiness, and negatively by Negative Affect. Finally, the "Attitude Towards Humor" is positively affected by Subjective Happiness and negatively by Negative Affect, that is, people with CKD with higher scores on "Attitude Towards Humor" present higher scores on Subjective Happiness and lower scores on Negative Affect.

\subsection{Implications for nursing educators and practice}

These results show structural differences compared to the original scale ${ }^{[12]}$ and the Portuguese language in the European version. ${ }^{[6,18]}$ They also suggest that it is a valid and reliable scale to evaluate the effect of multidimensional humor, in people with terminal stage CKD. This scale can provide important contributions to nursing interventions $(\mathrm{Hu}-$ mor $)^{[8]}$ related to sense of humor evaluation in patients with terminal stage CKD during hemodialysis session ${ }^{[5]}$ and it can be applied to people with chronic disease.

\subsection{Limitations and venues for future research}

Our main limitation was the nature of the study design as a cross-sectional study, as it may have conditioned the results of predictive validity. A longitudinal study is recommended to avoid bias. Also the lack of financial support limited the number of researchers involved in data collection. Therefore sample size was conditioned.
This study used a representative sample of individuals with CKD undergoing hemodialysis program. In future research it is important to conduct a confirmatory factor analysis in this specific population with a broader sample, a minimum of 300 people, and it is also important to understand how sense of humor affects patients' quality of life and decreases their stress and anxiety.

\section{Conclusion}

The Portuguese version of MSHS scale in patients with CKD has a structure consisting of three dimensions adjusted to this specific population: Production of humor and social use of humor; Adaptive Humor and Appreciation of humor; and finally Attitude Towards Humor. being proper and adjusted in this specific population.

However, in this study we couldn't find evidence that supports the original scale of four factors or even the five factors scale, such as the European Portuguese version.

MSHS shows evidence of being valid and reproducible when applied through both questionnaire and/or interview methods to patients with CKD, to evaluate the effect of multidimensional humor. It can also be used in patients with other chronic diseases.

The measurement of sense of multidimensional humor can be integrated in humor intervention in nursing at the time of the initial assessment and also to monitor responsive gains for nursing care within the area of health and well-being.

\section{CONFLiCTS OF INTEREST Disclosure}

The authors declare that they have no competing interests.

\section{REFERENCES}

[1] Levey AS, Coresh J. Chronic kidney disease. Lancet. 2012 Jan 20; 379(9811): 165-80. https ://doi.org/10.1016/S0140-673 6(11) 60178-5

[2] Frazão CM, Medeiros AB, e Silva L, et al. Nursing diagnoses in chronic renal failure patients on hemodialysis. Acta Paul Enferm. 2014 Feb; 27(1): 40-3. https://doi.org/10.1590/1982-019 4201400009

[3] Trbojević-Stanković J, Stojimirović B, Bukumirić Z, et al. Depression and quality of sleep in maintenance hemodialysis patients. Srp Arh Celok Lek. 2014; 142(7-8): 437-43. PMid:25233688 https ://doi.org/10.2298/SARH1408437T

[4] Rebollo Rubio A, Morales Asencio JM, Eugenia Pons Raventos M. Depression, anxiety and health-related quality of life amongst patients who are starting dialysis treatment. J Ren Care. 2017 Jun 1; 43(2): 73-82. https://doi.org/10.1111/jorc. 12195

[5] Bennett PN, Parsons T, Ben-Moshe R, et al. Laughter and humor therapy in dialysis. Semin Dial. 2014 Sep 1; 27(5): 488-93.
PMid:24467450 https://doi.org/10.1111/sdi.12194

[6] José H, Parreira P. Adaptação para português da escala multidimensional do sentido de humor (MSHS). Referência. 2008; Série II(6): 7-18.

[7] Sousa LM, José HM. Benefícios do humor na saúde: revisão sistemática da literatura. Enformação. 2016 Jun 16; 7: 22-32.

[8] Butcher HK, Bulechek GM, Dochterman JM, Wagner C. Nursing Interventions Classification (NIC). 6th Edition. Missouri: Elsevier Health Sciences; 2013 Dec 27.

[9] McCreaddie M, Payne S. Humour in health-care interactions: a risk worth taking. Health Expect. 2014 Jun 1; 17(3): 332-44. PMid:22212380 https://doi.org/10.1111/j.1369-7625.20 $11.00758 . \mathrm{x}$

[10] Haydon G, Riet PV. A narrative inquiry: How do nurses respond to patients' use of humour? Contemp Nurse. 2014 Feb 1; 46(2): 197-205. PMid:24787253 https://doi.org/10.5172/conu.2014.46.2 .197 
[11] Sousa LM, Marques-Vieira CM, Severino SS, et al. Fatores explicativos da apreciação de filmes cómicos em pessoas com doença renal crónica. Rev Invest Enferm. 2016 Apr; Série II(15): 49-55.

[12] Thorson JA, Powell FC. Development and validation of a multidimensional sense of humor scale. J Clin Psychol. 1993 Jan 1; 49(1): 13-23. https://doi.org/10.1002/1097-4679(199301 ) $49: 1<13:$ :AID- JCLP2270490103>3.0.CO;2-S

[13] Thorson JA, Powell FC. Sense of humor and dimensions of personality. J Clin Psychol. 1993 Nov 1; 49(6): 799-809. https://doi.org/10.1002/1097-4679(199311) 49:6<799: : AID-JCLP2270490607>3.0. CO;2-P

[14] Thorson JA, Powell FC, Sarmany-Schuller I, et al. Psychological Health and Sense ol Humor. J Clin Psychol. 1997 Oct; 53(6): 60519. https://doi.org/10.1002/(SICI) 1097-4679(199710) 5 $3: 6<605:$ :AID-JCLP9>3.0.CO;2-I

[15] Thorson JA, Brdar I, Powell FC. Factor-analytic study of sense of humor in Croatia and the USA. Psychol Rep. 1997 Dec; 81(3): 971-7. https://doi.org/10.2466/pr0.1997.81.3.971

[16] Boyle GJ, Joss-Reid JM. Relationship of humour to health: A psychometric investigation. Br J Health Psychol. 2004 Feb 1; 9(1): 51-66. PMid:15006201 https://doi.org/10.1348/13591070432277 8722

[17] Carbelo-Baquero B, Alonso-Rodriguez MC, Valero-Garces C, et al. A Study of Sense of Humor in Spanish and American Samples. N Am J Psychol. 2006 Dec 1; 8(3): 447-54.

[18] José H, Parreira P, Thorson JA, et al. A factor-analytic study of the multidimensional sense of humor scale with a Portuguese sample. N Am J Psychol. 2007 Dec 1; 9(3): 595-610.
[19] Ho SK, Chik MP, Thorson JA. Psychometric Study of a Chinese Version of the Multidimensional Sense of Humor Scale. N Am J Psychol. 2008 Jun 1; 10(2): 425-34.

[20] Villarreal A, González M, Candia G. Validación de la escala del sentido del humor en población mexicana. Revista Psicologia Cientifica. com [serial on the Internet]. 2012; 14(1). Available from: http://www.psicologiacientifica.com/escala-del -sentido-del-humor-validacion-mexico

[21] Sousa LM, Marques-Vieira CM, Severino SS, et al. Validation of the Positive And Negative Affect Schedule in people with chronic kidney disease. Texto \& Contexto Enferm. 2016 Dec 20; 25(4): e5610015-1. https://doi.org/10.1590/0104-07072016005610015

[22] Sousa LM, Marques-Vieira CM, Severino SS, et al. Validation of the Subjective Happiness Scale in people with Chronic Kidney Disease. Enferm Global. 2017 Jun 29; 16(3): 60-70. https: //doi.org/10.6018/eglobal.16.3.266571

[23] Sousa LM, Marques-Vieira CM, Severino SS, et al. Validación del Índice de Bien-estar Personal en personas con enfermedad renal crónica. Enferm Nefrol. 2016 Jul 6; 19(2): 135-41.

[24] Lima DVM. Research design: a contribution to the author. Online Braz J Nurs [serial on the Internet]. 2011 [cited 2017 Aug 19]; 10(2). Available from: http://www.objnursing.uff.br/index.php/ nursing/article/view/3648/html_2

[25] Sousa LM, Marques-Vieira C, Carvalho ML, et al. Fidelidade e validade na construção e adequação de instrumentos de medida. Enformação. 2015; 5: 25-32.

[26] Diener E, Suh EM, Lucas RE, et al. Subjective well-being: three decades of progress. Psychol Bull. 1999 [cited 2017 Oct 30]; 125: 276-302. Available from: http://web.yonsei.ac.kr/suh/fil e/Subjective $\% 20$ Well $\% 20$ Being_Three $\% 20$ Decades $\% 20$ of $\% 2$ OProgress\%20-Diener, \%20Suh, \%20Lucas\&Smith.pdf 